Aus dem Städtischen Hygienischen Institut (Direktor: Prof. M. Neisser) und der Medizinischen Klinik des Städtischen Krankenhauses in Frankfurt a. M. (Direktor: Prof. Schwenkenbecher).

\title{
Zur Bedeutung des Vorkommens von Diphtheriebazillen im Harn.
}

Von Dr. R. Koch, Assistenzarzt der Klinik.

Conradi und Bierast ${ }^{1}$ ) haben die Urine von 155 Diphtheriekranken untersucht und darin in 54 Fällell, also bei jedem dritten Patienten, Diphtheriebazillen nachweisen können. In sechs Fällen wurde die Virulenz der gezüchteten Stämme durch den Tierversuch erprobt und bestätigt gefunden. Die Untersucher schließen aus diesem Ergebnis, allerdings unter Berücksichtigung der meist sehr spärlichen Anzahl der Keime unter großem Vorbehalt, auf die Bedeutung dieses Befundes für die Verbreitung der Diphtherie a uf dem Wege der Nahrungsmittelinfektion durch den Urin.

Unsere Resultate unterscheiden sich von den oben angeführten im wesentlichen dadurch, daß es sehr viel seltener gelungen ist, in den Urinen Diphtheriekranker einen Befund zu erheben, den wir als ,Diphtheriebacillus" anerkennen konnten. Wir glaubten im Gegensatz zu Conradi und Bierast ein Stäbchen, das im Urin auftritt, nur dann als Diphtheriebacillus identifizieren zu können, wenn es sich im Kulturverfahren und Tierversuch als solches erwies. Denn melır oder weniger diphtherieähnliche Stäbchen, die Doppelfärbung annehmen, findet man auch in den Urinen nicht Diphtheriekranker nicht selten. So konnten wir bei der Untersuchung von 19 Urinen Scharlachkranker, die bestimmt frei voll Diphtherie warell, viermal vereinzelte doppelt färbbare Stäbchen auf der Löfflerplatte züchten, die teilweise dem Diphtheriebacillus recht ähnlich sahen. Eine Reinzüchtung dieser spärlichen Keime ist nicht gelungen. Außerdem ist es gewiß berechtigt, eine genauere Prüfung der im Urin gefundenen diphtherieverdächtigen Stäbchen zu verlangen als der in den Rachenabstrichen nachgewiesenen. Deun das morphologische Verhalten der auf dell Rachenorganen vorkommenden diphtheroiden Stäbchen ist nachgerade den Untersuchern so gut bekannt geworden, dalis sie in den meisten Fällen auch ohne Reinzüelitung und ohne Tierversuch den auf der Löfflerplatte gefundenen pathogemen Keim mit einem so hohen Grade von Sicherheit erkennen köınen, daß eine Verwechslung kaum vorkommt. Außerdem erleichtert hier die große Zahl der Keime und Kolonien dio Diagnose. Die Diphtheroiden aber, die im Urin vorkommen, sind vorläufig noch wenig gekannt, ihre Eigentünllichkeiten und Unterscheidungsmerkmale von ähnlichen Orgauismen sind hier unerforscht, und die Zahl der zur Diagnose kommenden Keime ist äußerst gering. Es muß deshalb zurzeit noch ein großer Unterschied gemacht werden zwischen doppelt färbbaren Stäbchen im Urin, die eventuell Diphtheriebazillen sein können, und solchen, von denen wir mit Bestimmtheit sagen können, daß es Diphtheriebazillen sind. Deswegen ist zurzeit

Pferde- etc. Serum als solchem, nicht aber dem darin enthaltenen Anti toxin zuzuschreiben. $\mathrm{Ob}$ die Zahl, dic auf dem Fläschchen steht mit zwei oder mit vier Nullen sich schreibt, ist dabei ganz gleichgïltig. Und was dic vielfach gefürchtete, neuerdings so genannte Anaphylaxi betrifft, so ist das ein Schreckgespenst, das wohl nur die wenigsten, die mit den Serum arbeiten, selbst erleben. Fs wäre un der Zeit ihm zut Grund statistischer Daten einnal das Jebenslichi auszublasen.

1) Diese Wochenschrift 1912, Nr. 34, S. 1580. 
bei der Diagnose Diphtherie aus dem Urin noch Vorsicht gehoten.

Wir haben 111 Urine von 26 Patienten untersucht und dabei nur aus 4 Urinen, die von 2 Patienten stammten, tiervirulente Diphtheriebazillen züchten können. In weiteren 10 Urinen von 5 Patienten konnten wir auf der Löfflerplatte diphtherieverdächtige Stäbchen nachweisen, deren Reinzüichtung entweder nicht gelang oder zu einem uncharakteristischen, avirulenten Stamme führte. Im Originalpräparate der Zentrifugate fanden wir niemals wirklich diphtherieverdächtige Gebilde.

Unsere Urine stammten fast ausschließlich von Kindern. Der Urin wurde, nach vorhergehender gründlicher Reinigung der Harnröhrenmündung mit Sublimat, in ein steriles Glas entleert. Es ist gewiß angebracht, daran zu erinnern, wie leicht auf einer Diphtherieabteilung eine Infektion des schon gelassenen Urins im Gefäße durch Patienten und Pflegepersonal vorkommen kann. Diese sowie eine Verunreinigung nit der an äußeren Genitale wuchernden Flora glauben wir ausgeschlossen zu haben. Dem einen erwachsenen männlichen Patienten überließ die Schwester die oben geschilderte Prozedur selbst. Wir fanden bei ihm unter neun Untersuchungen viermal verdächtige Stäbchen. Einen steril mit Katheter entnommenen Urin fanden wir dann frei von solchen Gebilden.

Eine Uebersicht unserer Befunde gibt folgende Tabelle:

I. Leichte und mittelschwere Fälle mit Ausgang in Heilung.

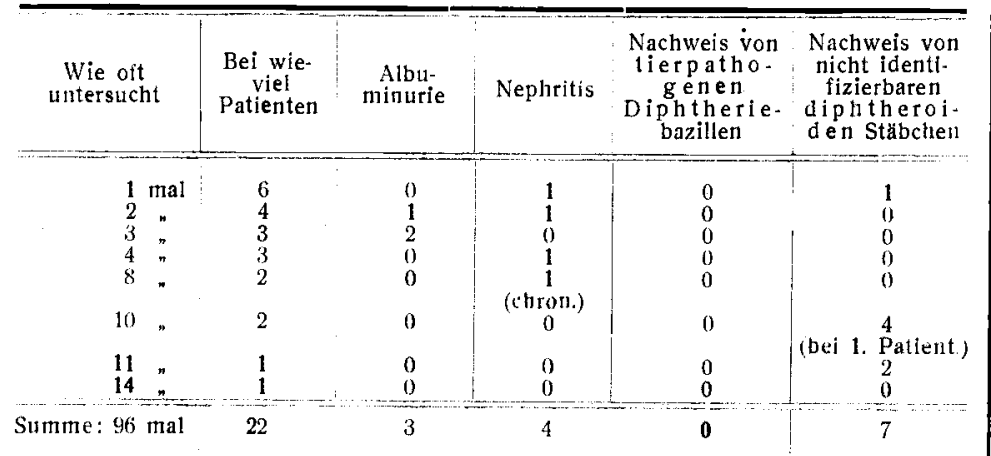

II. Sehwere Fälle dureh Herz- und Gefäßlähmung tödlich ondeud,

\begin{tabular}{cc|c|c|c|c}
2 mal & 2 & 0 & 2 & 0 & 3 \\
$4 \%$ & 1 & 0 & 1 & 1 & 0 \\
$7 n$ & 1 & 0 & 1 & 3 & 0 \\
\hline Summe: 15 mal & 4 & 0 & 4 & 4 & 3
\end{tabular}

Es geht daraus zunächst hervor, daß wir bei 19 Patienten in zusammen 74 Untersuchungen einen rein negativen Befund crheben konnten. Von diesen 19 negativen Fällen sind einige recht häufig untersucht, am häufigsten Fall 20, bei dem wir don Urin in einem Zeitraum von 25 Tagen 14 mal untersuchten. Diese 19 Fälle sind meist leichte und mittlere oder nur lokal starke Diphtherien gewesen, mit Ausnahme eines nur 1 mal untersuchten Falles, der Anzeichen einer leichten Allgemeinintoxikation darbot.

Die in unserem Sinne positiven Befunde, also Befunde von tiervirulenten Bazillen, haben wir bei zwei Patienten erhoben, die beide das schwerste Bild der Allgemeinintoxikation darboten und an Herz- und Gefäßlähmung istirben.

Bei dem ersten dieser Fälle kamen vol is il bazillenlualtigen an zwei verschiedenen Tagen bazillenfreie Urine zur Untersuchung. Der Tag des Auftretens der Keime, der siebente Krankheitstag, stand in keiner Bezichung zum klinisehen Verlauf der Erkrankung. Der Zustand des Kindes war voll vornherein sehwer. Eine leiehte Nephritis lestand sehon tagelang vorher. Der jähe Pulsabsturz setzte erst diei Tago später ein und führte am Morgen dos näehsten Tages zum Tode. I)as Kind war früh, am zweiten Krankheitstage, in Behandlung gekommen und mit einer sehr hohen Seruundose (18 000 Immunitätseinheiten) innerhalb der ersten beiden Behandlungstage gesprityt worden.

Der zweite Fall ist ähnlich. Hier wurden die Bazillen gleich bei der ersten Untersuchung anı fünten Krankheitstage gefunden. Diphtheriebazillen wurden außerdem am nächsten Tage,. nicht aber bei vier Unter'suchungen wälırend der nächsten fünf Tage gefunden. Erst am zwölften Krankhleitstage, am Tage vor dem Tode, traten sic wicder wuf. In der Leiche des Kindes komnten Jiphthericbarillen nicht nish- gewiesen werden. Auch hier ist der Bazillenbefund unabhängig vou Aenderungen im klinischen Verlaufe aufgetreten. Das Einsetzen der schweren Nephritis sowie die Pulssenkung sind an Tagen aufgetretell, in denen der' Urin bazillenfrei war. Dieses Kind war spät, am vierten Krankheitstage, mit den allersehwersten örtlichen nnd allgemeinen $\mathrm{Es}^{\mathrm{r}}$ scheinungen in Behandlung gekommerl. Es hatte sofort $12000 \mathrm{Im}$ munitätseinheiten erhalten, davon 3000 intravenös.

Die übrigen fünf Patienten mit durch Tierversuch nicht identifizierbaren Stäbchen scheiden aus den oben angeführten Gründen aus der Erörterung aus. Es kann nicht von mehr als der Möglichkeit gesprochen werden, daß einige dieser spärlichen Keime Diphtheriebazillen waren. Das Ergebnis unserer Kontrolluntersuchungen an Scharlachurinen macht es aber gewiß. daß unter einer so großen Anzahl untersuchtor Urine eine ganze Reihe diphtherieähnlicher Stäbchen enthalten sein kann, dic mit Sicherheit keine Diphtheriebazillen sind. Unter diesen fünf Patienten hatte der eine eine leichte, zwei schwere Rachendiphtherien, die beiden übrigen waren allerschwerste, früh tödlich endende Fälle, die ganz unseren Fällen mit positivem Bazillenbefund entsprachen. Bei dem einen wurden nach dem Tode aus der Halslymphdrüise und der Milż tiervirulente Diphtheriebazillen gezuichtet, bei dem anderen ist dies nicht gelungen. Bei beiden wurde postmortal Urin durch sterile Punktion der Blase entnommen, der sich als diphtheriebazillenfrei erwies.

Es geht außerdem aus der Tabelle hervor, daß die Bazillenausscheidung unabhängig von nachweisbaren Nierenveränderungen vor sich geht. Wir haben eine ganze Reihe von Albuminurien und Nephritiden bazillenfrei gefunden, während der eine der tierpositiven Stämme aus einem eiweißfreien Urin gezüchtet wurde. Allerdings war am Tage vorher eine leichte Albuminurie, an Tage nachher eine schwere Nephritis aufgetreten.

Unser Material ergibt also, daß die Ausscheidung nachweisbarer Mengen von Diphtheriekeimen durch den Urin wohl vorkommt, aber eine seltene Erscheinung ist, die sich vorzugsweise bei allerschwersten Fällen zeigt. Deshalb dürfte wohl die allgemeine Bedeutung der Diphtheriebayillenausscheidung durch den Urin für die Prophylaxe der Diphtherie nicht sehr hoch einzuschätzen sein. Denn die schwerkranken Diphtheriepatienten sind bettlägerig und haben kaum Gelegenheit, ihren Urin mit einer Materie in Verbindung $\mathrm{zu}$ bringen, die zu einer Verschleppung der Keime geeignet wäre. Dic leichten Kranken aber scheiden, wie ja auch die überwiegende Mehrzahl der Fälle von Conradi und Bicrast, so wenig Stäbchen aus, daß - vorausgesetzt, daß es sich manclimal um Diphtheriebazillen handelt — eine Infektion wohl kaum in Betracht kommt. Denn wenn es auf der Löfflerplatte zu keinem rechten Wachstum kommen will, ist nicht anzunehmen, daß die Keime etwa in der Milch so viel bessere Existenzbedingungen antreffen. Jedenfalls ist die Möglichkeit der Infektion der Milch und anderer Nahrungsmittel durcl hineingelangten Speichel, durch Rachen- und Nasensekret unverhältnismäßig größer.

Die Frage der Dauerausscheidung durch Bazillenträger: konnten wir leider an geeignetem Material nicht prïfen. Immerhin haben wir ein Kind untersucht, bei dem im Rachen vier Wochen lang Diphtheriebazillen nachweisbar waren. Dies Kind wurde in 25 Tagen 14 mal untcrsucht, ohne daß ein einzigesmal diphtherieverdächtige Stäbchen gefunden werden konnten. Ucbrigens macht das Ergebnis unserer Untersuchungen, nacl dem die Bazillonausscheidung im schwersten Stadiun der Krankheit aufzutreten scheint, die Dauerausscheidung durch den Urin der Bazillenträger in hohen Grade unwahrscheinlich.

Für die Klinik der Diphtheric ist der von Conradi und Bierast zuerst erhobene Befund auBerordentlich interessant. Daß eine spezifische Bakteriänie bei Diphtherie auftreten kann, war aus Untersuchungen an der Leiche und neverdings auch am Lebenden bekannt. Unsere Befunde bestätigen, daß diese Bakteriämie nicht agonal zu sein braucht, sic wurden an achten. siebenten, fünften und ersten Tage vor dem Tode erhoben. Es zeigt sich aber: weiter, da n nachweisbarc Mengen von Diphtherichazillen anscheinend nur bei solchen 
Fällen auftreten, die unter dem Bilde der Allgemeinintoxikation tödlich verlaufen, ohne daß aber in jedem solchen Falle der Nachweis der in den Kreislauf gelangten Bazillen gelingen muß. Dafür, daß die Invasion in die Blutbahn an der Schwere der Erkrankung beteiligt ist, läßt sich aus dem vorliegenden Material ein Anhaltspunkt nicht gewinnen. Hingegen ergibt sich mit Sicherheit, daß die Ausscheidung der Keime eine nur gelegentliche und spärliche ist. Erwähnen will ich noch, daß die Verschiedenheit der Technik in unseren und in den ConradiBierastschen Versuchen zur Erklärung der differenten Ergebnisse nicht herangezogen werden kann, da ja bei Urin ein Ueberwuchern etwa vorhandener Diphtheroider nur selten vorkommt.

Jedenfalls verdient die wichtige, von Conradi-Bierast zuerst behandelte Frage weitere Beachtung.

Zusammenfassung. Es wurden 111 Urinproben von 26 Diphtheriepatienten untersucht. Darunter wurden in 4 Urinproben bei 2 Patienten tierpathogene Diphtheriebazillen gefunden. In 10 Urinproben von 5 Patienten wurden vereinzelte diphtheroide Stäbchen gefunden, deren Identifizierung nicht gelang. Ebensolche vereinzelte diphtheroide Stäbchen wurden unter 19 Urinproben von Scharlachkranken, die bestimmt frei von Diphtherie waren, 4 mal gefunden. Tierpathogene Diphtheriebazillen wurden nur bei Patienten gefunden, die im Frühstadium der Erkrankung an Herz- und Gefäßlähmung starben. 